\title{
After-sales services optimisation through dynamic opportunistic maintenance: a wind energy case study
}

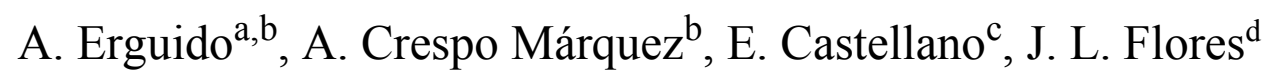

${ }^{a}$ Departamento de Organización Industrial y Gestión de Empresas I, Escuela Superior de Ingenieros, Universidad de Sevilla.

${ }^{b}$ IK4-Ikerlan Technology Research Centre, Operations and Maintenance Technologies Area, 20500 Gipuzkoa, Spain

${ }^{c}$ MIK Research Centre, Mondragon University, 20560 Gipuzkoa, Spain

${ }^{d}$ Dependable Embedded Systems Area, IK4-Ikerlan Technology Research Centre, Gipuzkoa, Spain

*Asier Erguido (corresponding author)

aerguido@ikerlan.es

$+34943712400$

Adolfo Crespo

adolfo@etsi.us.es

+34954487215

Eduardo Castellano

ecastellano@mondragon.edu

+34943718009

Jose Luis Flores

jlflores@ikerlan.es

$+34943712400$

\section{Funding}

The author(s) disclosed receipt of the following financial support for the research, authorship, and/or publication of this article: This work was performed within the context of the SustainOwner ('Sustainable Design and Management of Industrial Assets through Total Value and Cost of Ownership'), a project sponsored by the EU Framework Programme Horizon 2020, MSCARISE- 2014: Marie Sklodowska-Curie Research and Innovation Staff Exchange (RISE) (Grant number 645733-Sustain-Owner-H2020MSCA-RISE-2014) and the EmaitekPlus 2017-2018 Program of the Basque Government. 


\section{After-sales services optimisation through dynamic opportunistic maintenance. A Wind energy case study.}

\author{
Asier Erguido ${ }^{1,2}$, Adolfo Crespo ${ }^{2}$, Eduardo Castellano ${ }^{3}$ and Jose Luis Flores ${ }^{4}$
}

\begin{abstract}
After-sales maintenance services can be a very profitable source of incomes for original equipment manufacturers (OEM) due to the increasing interest of assets' users on performance-based contracts. However, when it concerns the product value-adding process, OEM have traditionally been more focused on improving their production processes, rather than on complementing their products by offering after-sales services; consequently leading to difficulties in offering them efficiently. Furthermore, both due to the high uncertainty of the assets' behaviour and the inherent challenges of managing the maintenance process (e.g. maintenance strategy to be followed or resources to be deployed), it is complex to make business out of the provision of after-sales services. With the aim of helping the business and maintenance decision makers at this point, this paper proposes a framework for optimising the incomes of after-sales maintenance services through: 1) implementing advanced multi-objective opportunistic maintenance strategies that sistematically consider the assets' operational context in order to perform preventive maintenance during most favourable conditions, 2) considering the specific OEMs' and users' needs, and 3) assessing both internal and external uncertainties that might condition the after-sales services' success. The developed case study for the wind energy sector demonstrates the suitability of the presented framework for optimising the after-sales services.
\end{abstract}

\title{
Keywords
}

After-Sales Services, Life Cycle Cost, Uncertainty Assessment, Dynamic Opportunistic Maintenance, Multi-Objective Optimisation, Wind Energy Sector

\section{Introduction}

After-sales service is fast becoming a key instrument in the relationship between the Original Equipment Manufacturers (OEM) and the assets users. In general, assets users are more frequently asking for such services, and the OEMs are willing to satisfy them due to the several benefits that they are able to obtain, such as: recurrent stream of revenues generated throughout the life cycle of the assets, which usually exceeds the profit margins of new equipment sales ${ }^{1}$; extra value added to sold equipment, used as a competitive differentiator ${ }^{2}$; increase of the assets users' satisfaction and loyalty ${ }^{3,4}$, etc.

Accordingly, many OEMs have already successfully integrated the after-sales services within their business, having transformed it in a business core ${ }^{2}$. Nevertheless, some others, such as machinery fabrication companies, have traditionally been more focused on new equipment design and sale rather than on offering after-sales services to their clients; having now difficulties in properly deploying such services $^{5}$.

The main problems when defining the after-sales services arise when the key factors that drive the system performance have to be identified and their influence on operational availability has to be meassured ${ }^{6}$. Furthermore, there are several uncertainty sources that have to be dealt with during the after-sales services deployment, such as cost or repair processes, which make it difficult to guarantee a determined service level and a price for providing it ${ }^{7,8}$.
In this context, the development of maintenance models plays a key role, since they enable to calculate the quality of the after-sales service (through reliability, availability and maintainability analysis), and the cost associated to that service (through life cycle cost (LCC) analysis); allowing to find a trade-off between the service level to be offered and its price. Moreover, when such maintenance models are developed, the impact of uncertainty sources can also be meassured, accurately providing the decision-maker with the necessary information to anticipate the risks to be handled within the after-sales service contracting. Accordingly, the after-sales service success and the satisfaction of every stakeholder involved in the contract will be fostered.

To the best of the authors knowledge, there is not previous research that 1) categorises the uncertainty sources to be dealt within the after-sales services, 2) analytically derives

\footnotetext{
${ }^{1}$ IK4-Ikerlan Technology Research Centre, Operations and Maintenance Technologies Area, 20500 Gipuzkoa, Spain

${ }^{2}$ Departamento de Organización Industrial y Gestión de Empresas I, Escuela Superior de Ingenieros, Universidad de Sevilla, Camino de los Descubrimientos s/n, 41092 Sevilla, España

${ }^{3}$ MIK Research Centre, Mondragon University, 20560 Gipuzkoa, Spain

${ }^{4}$ IK4-Ikerlan Technology Research Centre, Dependable Embedded Systems Area, 20500 Gipuzkoa, Spain
}

\section{Corresponding author:}

Asier Erguido, IK4-Ikerlan Technology Research Centre, Operations and Maintenance Technologies Area, 20500 Gipuzkoa, Spain

Email: aerguido@ikerlan.es 


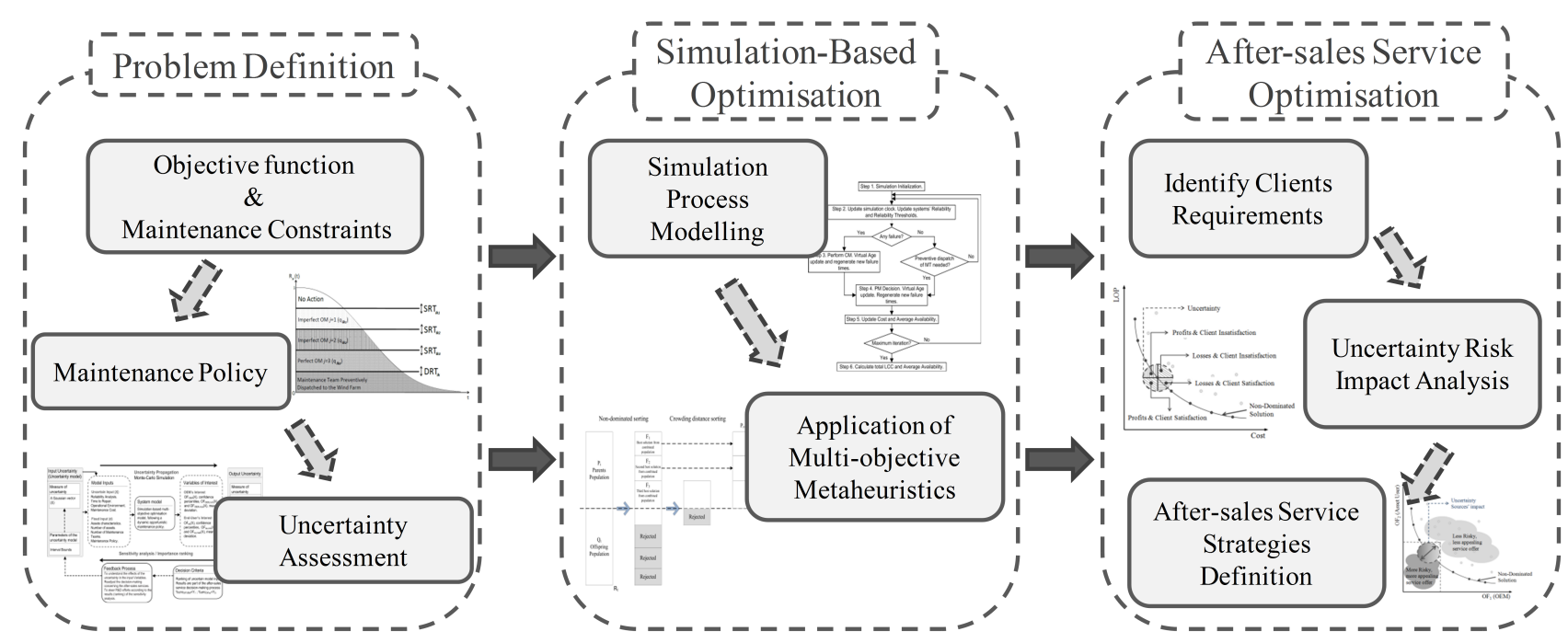

Figure 1. Proposed approach (figures are shown in detail during the paper)

their impact in terms of both the after-sales service level and its profitability and 3) provides managerial insights illustrated through a numerical experiment based on realfield data, enriching its practitioning approach.

Therefore, it is the aim of this paper to address these specific issues, for which different steps have been taken, classified into 3 main phases (see Figure 1):

1. Problem definition. Within this phase the maintenance problem is defined, identifying the maintenance constraints for deploying the after-sales service and the main objectives of both the OEM and the asset user. Likewise, the maintenance policy to be followed during the after-sales service is established and the main uncertainty sources are identified.

2. Simulation-based optimisation. Simulation techniques are used in order to handle the several stochastic processes to be born within the after-sales maintenance services and to evaluate the different strategies 9,10 . Since both the interests of OEM and assets users should be met by the defined after-sales maintenance services, a multi-objective metaheuristic is implemented for finding the efficient frontier of the service level vs cost curve (non-dominated optimal maintenance strategies), in a simulation-based optimisation approach ${ }^{11}$.

3. After-sales Service optimisation. Before offering the after-sales service, the asset users are characterised and their requirements are identified. Based on the two previous phases and with the aid of a sensitivity analysis, the impact of uncertainty sources on the aftersales service is analyzed, in order to be able to assess the economical risk of the after-sales service to be offered.

The paper is organized as follows. In section 2 a brief summary of the literature is performed. Section 3 addresses the uncertainty impact and assessment on the after-sales service. In section 4 the system model for managing the after-sales services in the wind energy sector is developed. In section 5 the computational results based on real field data are shown. Finally, section 6 summarizes the main conclusions of the research and establishes future research lines.

\section{State of the art}

The present work is associated with multiple literatures, but the three most directly related literatures are on aftersales services, uncertainty assessment and maintenance optimisation models (specifically applied to the wind energy).

\subsection{After-sales services}

To date, the literature has distinguished two different types of after-sales services ${ }^{6,7}$ : material contract and Performance Based Contracting (PBC). While under a material contract the asset users pay to the OEM the services related to the maintenance activity (i.e. spare parts or labour time), under the PBC a service level of the assets is ensured by the OEM at the asset user site.

Traditionally the most traditional service agreements have been related to material contracts. However, the paradigm is currently changing to PBC, due to the interest of assets users on the availability of their systems, rather than on the resources used for maintaining them ${ }^{7}$. Therefore, on this new context, the asset users will explicitly define the service level that they require, and the OEMs will determine how to fulfill that requirement ${ }^{13}$, e.g. defining their after-sales maintenance strategy.

The most widely used PBC payment forms can be classified as fixed or variable price:

1. Fixed payment method. There are two basic approaches according to the uncertainty related to the sold asset ${ }^{14}$ : fixed price, where the OEM assumes all the risk of the contract (asset with lower uncertainty), and cost plus fixed price, where the risk is assumed by the asset user (asset with higher uncertainty). In both cases, the OEMs will prefer to minimize the LCC of the commited service in order to maximize their profits $^{15}$.

2. Variable payment methods. The OEMs will be awarded if certain goals related to the service level are 


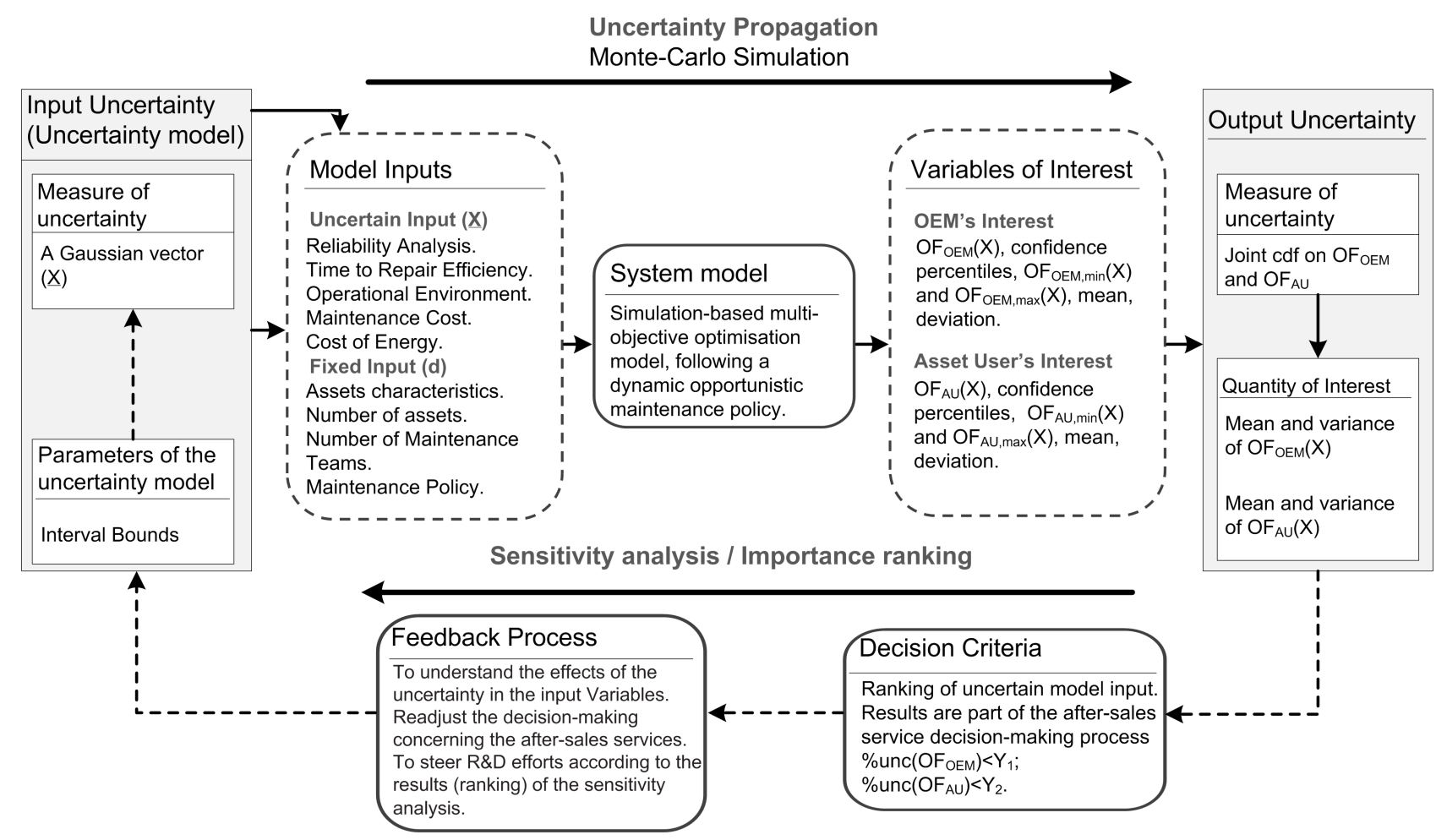

Figure 2. Uncertainty framework for after-sales services, adapted from ${ }^{12}$

achieved. Thus, OEMs will be focused on maximizing both their interests and the asset users' interests ${ }^{16}$.

In wind power industry, maintenance activities are usually performed by the OEM under a material contract, which implies lucrative revenues for the OEM. Nevertheless, such contract model generates financial pressures on the wind farmers and does not ensure the OEMs' efforts on improving their assets' reliability, which suggests that a change of paradigm to $\mathrm{PBC}$ will be given ${ }^{14}$. Under a $\mathrm{PBC}$, the asset users would be able to focus on their core business (delivering reliable and clean energy), while the OEMs would keep longer service agreement ${ }^{14}$.

\subsection{Uncertainty assessment}

There are plenty of uncertainty sources that might condition the after-sales service, jeopardising its success, and thus, the OEMs' profits and assets ussers' service level ${ }^{7}$. These uncertainty sources might be classified in endogenous, when the OEM has influence over the uncertainty source to a greater extent (technology, data quality, system model accuracy, etc.), and exogenous, when there is lesser influence over them (political and cultural context) ${ }^{17}$.

Both endogenous and exogenous uncertainties should be considered within the uncertainty analysis. However, the decision-makers' efforts should be rather focused on minimising the formers ${ }^{12}$ in order to reduce the risk of the after-sales service deployment; understanding the risk as the effect of uncertainty impact on OEMs' and assets users' objectives $^{18}$.

Generally, these uncertainties, which are quantified through statistical analysis and confidence or tolerance intervals ${ }^{19,20}$, should be assessed in industrial practice at different levels ${ }^{12}$ (see Figure 2):
1. The system model, which aims to numerically describe the real industrial problem and obtain some outputs (variables of interest) according both to fixed and uncertain inputs (developed in Section 4).

2. Uncertainty sources, which might appear both in the inputs parameters and in the system model, and will propagate the uncertainty until the output (respectively studied in Sections 3 and 5).

3. Actions related to the decision making process regarding the feedback process based on the analysis of the uncertainty impact on the quantities of interest (see Section 5).

Likewise, the general goals when assessing them can be classified in ${ }^{12}$ : to understand the influence of uncertainty on model in order to improve the decision making-process; to accredit a certain level for accepting the use of a model; to compare relative performance and select the best maintenance policy or operation of the system; and to comply or demonstrate that a certain criterion is met.

For the present research, the main goals will be related to identify and assess the main uncertainty sources related with the after-sales services, mainly generated by the maintenance processes and strategies adopted ${ }^{7}$. Therefore, it will be possible to meassure the risk of the different after-sales services to be deployed, comparing them and selecting the most appropriate one. Likewise, as a further result, the decision-maker will be able to rank the uncertainty sources, and thereby guide their decisions in order to reduce them.

\subsection{Maintenance optimisation models}

As stated, in order to succesfully structure the after-sales service, it is necessary to develop adequate maintenance 
Table 1. Nomenclature and Acronyms definition

\begin{tabular}{|c|c|c|c|}
\hline \multicolumn{4}{|c|}{ Nomenclature } \\
\hline$L C C$ & Life Cycle Cost & $w_{i k}$ & Reactivity weight \\
\hline$L P$ & Loss of Power & $K$ & Number of FM considered for each system \\
\hline$O F$ & Objective Function & $J$ & Levels of PM types considered for each FM \\
\hline$W F$ & Wind Farm & $G R P$ & Generalized Renewal Process \\
\hline$W T$ & Wind Turbine & $V A_{\text {hikt }}$ & Virtual age associated to FM $k$ in system $i$ in WT $h$ in \\
\hline$F M$ & Failure Mode & & period $t$ \\
\hline$C M$ & Corrective Maintenance & $\alpha_{i k}$ & Weibull scale parameter of FM $k$ of system $i$ \\
\hline$P M$ & Preventive Maintenance & $\beta_{i k}$ & Weibull shape parameter of FM $k$ of system $i$ \\
\hline$O E M$ & Original Equipment Manufacturer & $q_{i k j}^{p r}$ & Restoration factor of $j$ PM level on system $i$ for FM $k$ \\
\hline$A U$ & Asset user & $q_{i k}^{c}$ & Restoration factor of CM on system $i$ for FM $k$ \\
\hline$T T F$ & Time To Failure & $N T$ & Number of MTs \\
\hline$M T$ & Maintenance Team & $c_{i k}^{c}$ & Cost of tools and materials needed for performing $\mathrm{CM}$ \\
\hline$v_{t}$ & Average wind speed in period $t$ & & of FM $k$ in system $i$ \\
\hline$G P_{t}$ & Generated Power in period $t$ & $c_{i k j}^{p r}$ & Cost of tools and materials needed for performing $\mathrm{PM} j$ \\
\hline$R P$ & Rated Power of the WT & & of FM $k$ in system $i$ \\
\hline$R_{i k}(V A)$ & Reliability of system i and FM k at virtual age VA & $c^{\text {team }}$ & Cost of MT \\
\hline \multirow[t]{2}{*}{$S R T_{i k j}$} & Fixed Reliability Threshold for applying perfect or & $c^{e t}$ & Extra time cost \\
\hline & imperfect $\mathrm{PM} j$ on system $i$ and $\mathrm{FM} k$ & $c^{\text {disp }}$ & cost of maintenance dispatch \\
\hline \multirow[t]{2}{*}{$S R T_{i k j t}$} & System Reliability Threshold in period $t$ for applying & $c^{n a}$ & cost of No Availability or opportunity cost \\
\hline & perfect or imperfect PM $j$ system $i$ and FM $k$ & $c^{p}$ & Penalty cost due to unplanned maintenance \\
\hline$D R T_{i k}$ & Fixed Dispatch Reliability Threshold & $m_{i k}^{c}$ & Maintainability of CM for FM $k$ in system $i$ \\
\hline$D R T_{i k t}$ & Dispatch Reliability Threshold in period $t$ & $m_{i k}^{p r}$ & Maintainability of PM for FM $k$ in system $i$ \\
\hline \multirow[t]{2}{*}{$V$} & Wind speed threshold for determining reliability & $C$ & Capacity of each MT (in hours) \\
\hline & thresholds variation & $N T^{\max }$ & Maximum number of MTs \\
\hline$p$ & Periods of time considered for wind speed forecasting & $T$ & Maximum iteration periods \\
\hline
\end{tabular}

models that find the efficient frontier of the service quality vs cost curve ${ }^{2}$.

Wang's comprehensive review ${ }^{21}$ about the maintenance optimisation models classifies them into two main categories: single-unit systems and multiple-unit systems. In both cases, the maintenance decision making process relies on the usual indicators, such as, assets' age, reliability, number of failures, etc. However, the formers tend to overlook the fact that the assets are very complex, consisting of several systems and subsystems, which can present economical, structural or stochastic dependences among them that condition the maintenance performance $\left(\mathrm{see}^{22}\right)$.

In this context, multiple-unit maintenance policies, which consider such dependencies, enable to find more suitable maintenance solutions ${ }^{21}$. Accordingly, there has been a growing interest in the utilisation, modelling and optimisation of such maintenance policies.

It is the case of opportunistic maintenance, which due to its capacity for including short term information in order to improve maintenance performance ${ }^{23}$, has been widely researched lately ${ }^{24}$. According to Ba et al. ${ }^{25}$, the short term information included within the opportunistic maintenance can be both regarding internal, e.g.. assets dependences, and external factors, e.g. production schedule. In the specific context of the after-sales service offer, external factors play a key role, since beyond the dependences among the assets, the needs of the assets users should be continuously regarded within the maintenance decision making process.

On the particular case of the wind energy sector, opportunistic maintenance policies have been widely researched as well, mainly favoured by the economical dependences among the wind turbines ${ }^{26}$. Nevertheless, to date, researches on opportunistic maintenance in the wind energy sector have been mainly related to the internal factors, rather than to external factors: redundancies ${ }^{27}$, condition monitoring systems ${ }^{26,28,29}$, multi-level maintenance ${ }^{30,31}$, etc.

Therefore, on this specific research, the novel dynamic opportunistic maintenance prosposed by the authors has been adopted, since it enables to consider both internal and external factors, more suitable for the after-sales service context.

\section{Uncertainty assessment on the after-sales service}

In order to be able to manage the several uncertainty sources that might jeopardize the success of the afer-sales service deployment, the framework for assessing the uncertainty in industrial practices proposed by Rocquigny et al. ${ }^{12}$ has been adopted and particularised for this specific application in Figure 2.

In the particular case of the after-sales services, the propagation and impact of the uncertainty sources in the variables of interest should have a double perspective, since the output of the model should consider both the OEMs' and the asset users' interests, which could respectively be the minimization of service cost and minimization of service disruptions (see Figure 2).

Figure 3 illustrates the impact that the uncertainty sources might have in practice: whereas the model should give an after-sales strategy that optimises both the OEMs and the assets users interests (non-dominated solution), in the practice, this solution will not be so accurate -due to the 


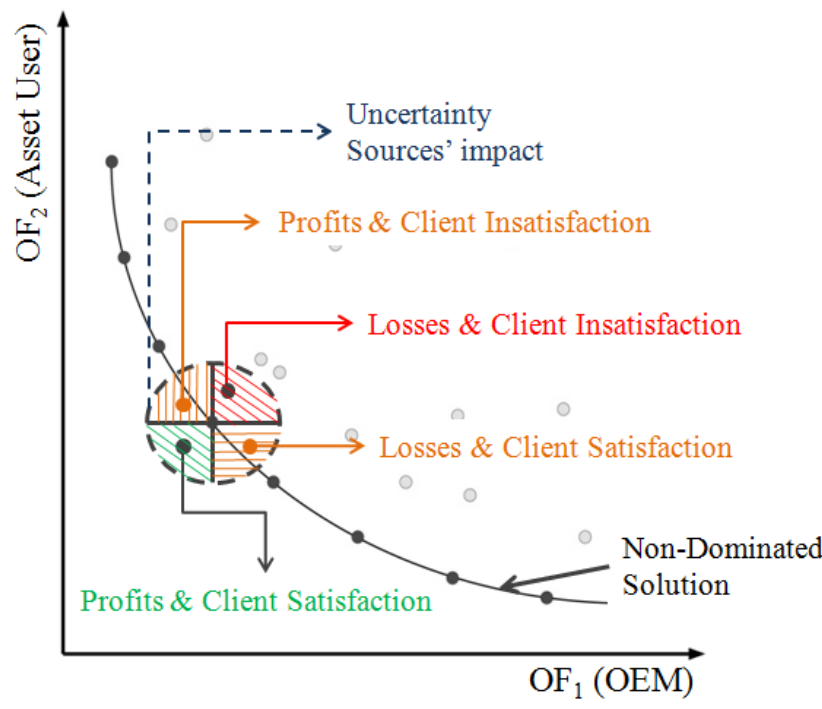

(a) Uncertainty influence on OEM s' and Asset Users' Interests

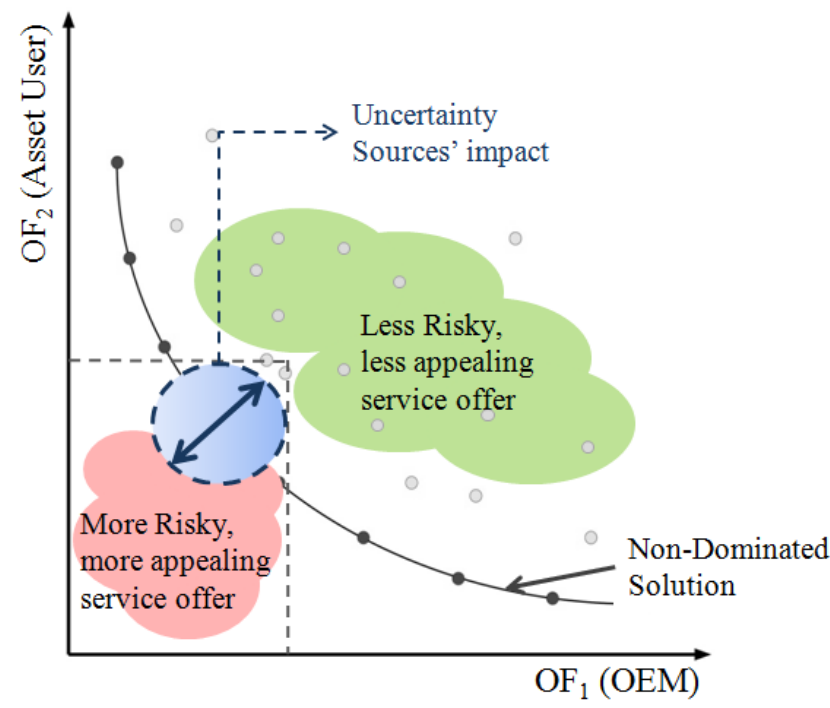

(b) Service Appeal for the asset user VS Risk of the after-sales service success

Figure 3. Uncertainty impact on the after-sales service

uncertainty sources-, being probable to provide a final output that does not meet stakeholders' interests.

Accordingly, the uncertainty might lead to different scenarios depending on the output variables results: both the OEM and the asset user are satisfied, neither of them are satisfied, or only one of them is satisfied (see Figure 3a). Since every stake has to be satisfied by the after-sales service in order to consider it successfull, it is essential to meassure the impact of the uncertainty sources within the interest variables; otherwise the success of the after-sales service will be jeopardised. This impact, which in Figure 3 has been represented through the diameter of the circle, can be meassured by analyzing the joint probability distribution function of the interest variables (see Figure 2).

The OEM should be aware of this uncertainty impact within the definition of the after-sales service, in order to search an scenario where both the OEM and the asset user are satisfied. In fact, decisions very conservative from the OEM perspective (higher service cost, lower service level) might lead to an after-sales service less appealing for the asset users, and viceversa (see Figure $3 b$ ). Thus a trade-off should be found between offering an appealing service for the assets users and a successfull after-sales service.

Furthermore, once the OEM is able to quantify the uncertainty impact, they will be able to rank the uncertainty sources according to their impact on the variables of interest through sensitivity analysis. Consequently, they will be able to focus their research efforts on reducing these uncertainties and their impact, specially regarding the endogenous uncertainties, and offering more appealing and less risky after-sales services in the future.

\section{System model for managing after-sales services in the wind energy sector}

On this section, the whole system for managing the aftersales service in the wind energy sector is modelled, defining the specific problem, maintenance policy to be followed, deriving the analytical formulation of OEMs and asset users quantities of interest and the optimisation problem.

\subsection{Problem definition}

The wind farm (WF) consists of $H$ wind turbines (WTs) of similar characteristics that have $N$ critical systems connected in series. Each system might fail in $k$ different failure modes (FMs) classified according to their severity $(k=1,2, \ldots, K)$, for which in case of failure, $k$ corrective maintenance (CM) will be performed. Likewise, prior to a failure occurrence, systems can undergo different preventive maintenance (PM) levels, either perfect or imperfect $(j=1,2, \ldots, J)$.

When the PM activity restores the system to an operational condition worse than the new one but better than just before the maintenance task is performed, it will be considered an imperfect action. However, if the PM restores the system to an operational condition as good as the new one, i.e. replacement, it will be considered a perfect action see $^{32}$ for further information). Accordingly, in this research $j=J$ is considered a perfect repair and $j=1$ the most imperfect repair.

Among the several studies that have investigated the restoration effect of maintenance $\left(\mathrm{see}^{32}\right)$, the Generalized Renewal Process (GRP) proposed by Yañez et al. ${ }^{33}$ is specifically utilised in the present problem. The GRP provides flexibility for modelling both the behaviour of the systems before failures and the quality of repairs during the different life stages of the systems by the definition of two main concepts (see Eq.1):

- Rejuvenation parameter $\left(q_{i j}=[0,1]\right)$, which is associated to the efficiency of the restoration effect of the maintenance activity $j$ on the system $i$ ( $q=0$ for the most imperfect maintenance and $q=1$ for perfect maintenance)

- Virtual age $(V A)$, which identifies the system's age after being repaired, and thus, it's reliability. 


$$
V A_{i}^{\text {new }}=V A_{i}^{\text {old }}\left(1-q_{i j}\right)
$$

Accordingly, after an imperfect repair, failure probability distribution conditioned to the survival of the new virtual age is calculated through Eq.2. Due to the suitability of the Weibull distribution when modelling the WTs' systems' reliability ${ }^{34,35}$, Eq. 2 has been ad hoc particularized in Eq.3 according to the scale $\left(\alpha_{i k}\right)$ and shape parameters $\left(\beta_{i k}\right)$ that define the Weibull distribution for each FM $k$ of system $i$ (the reader is addressed to ${ }^{33}$ for further information):

$$
\begin{aligned}
F\left(t \mid V A_{i}^{\text {new }}\right)=P\left[T_{i j} \leq t \mid T_{i j}\right. & \left.>V A_{i}^{\text {new }}\right] \\
& =\frac{F(t)-F\left(V A_{i}^{\text {new }}\right)}{1-F\left(V A_{i}^{\text {new }}\right)}
\end{aligned}
$$

$$
\begin{aligned}
R\left(t \mid V A_{h i k}^{\text {new }}\right)= & 1-F\left(t \mid V A_{h i k}^{\text {new }}\right) \\
& =\exp \left[\left(\frac{V A_{h i k}^{n e w}}{\alpha_{i k}}\right)^{\beta_{i k}}-\left(\frac{t}{\alpha_{i k}}\right)^{\beta_{i k}}\right]
\end{aligned}
$$

Likewise, both fixed and variable maintenance costs are considered in the problem. According to the formers, performing any maintenance implies a relevant dispatch cost $\left(c^{d i s p}\right)$, a material cost $\left(c_{i k}^{c}, c_{i k}^{p r}\right)$, an opportunity cost $\left(c^{n a}\right)$ in terms of not produced energy, a penalty cost $\left(c^{p}\right)$ in case a failure hinders the distribution of commited energy, and an extra cost $\left(c^{e t}\right)$ regarding outsourced maintenance activities if there are not own resources available for performing CM. In fact, own human resources, which consist of a number of maintenance teams $\left(N T^{\max }\right)$ with a certain capacity $(C)$, are considered to be the main fixed cost $\left(c^{\text {team }}\right)$. Both own and outsourced resources will directly depend on the required time to repair the systems, according to the maintainability of each FM $\left(m_{i k}^{c}, m_{i k}^{p r}\right)$.

Finally, without loss of generality, some assumptions have been made for the problem formulation:

1. Degradation processes of the systems are considered independent from each other and they are associated to the operation time (ageing systems, with increasing failure rate).

2. Data pooling procedure has been followed for performing the reliability analysis, since the fleet of WTs within a WF can be considered identical according to the coupling factors proposed by Stamatelato et al. ${ }^{36}$

3. Reliability of the FMs follows the Weibull distribution, with scale parameter $\alpha$ and shape parameter $\beta$.

4. Maintenance activities should be finished during the period of time in which they are started.

5. A maintenance dispatch is considered per period of time, where several maintenance teams (MTs) can be dispatched.

6. PM is assumed to be less resource-consuming than CM.

7. WF maintenance managers make decisions in discrete time and frequently ${ }^{37}$.

\subsection{Dynamic opportunistic maintenance policy}

In this study, the dynamic opportunistic maintenance policy proposed by the authors ${ }^{38}$ is followed, since it enables to consider within the maintenance decision making process short term information regarding both internal and external factors, through the economic dependency among the WTs ${ }^{39,40}$ and their specific operational context respectively. To this aim, the maintenance decision making process relies on two different dynamic reliability thresholds levels, which will release the maintenance activities based on the reliability of the FMs (see Figure 4):

- Dispatch reliability threshold $\left(D R T_{i k t}\right)$ : it determines whether a maintenance team should be preventively dispatched to the WF for performing PM, ensuring a minimum reliability for each FM and system.

- System reliability threshold $\left(S R T_{i k j t}\right)$ : once a maintenance team has been dispatched to the WF, it determines whether PM level $j$ should be performed during period $t$ for preventing FM $k$ of system $i$.

The novelty of the dynamic maintenance policy remains on systematically considering the operational context of the assets, dynamically recalculating the reliability thresholds' value in order to release the maintenance activities during most suitable operational contexts. In the particular case of the wind energy case study, there are several reasons for trying to avoid the performance of PM during high wind speed periods:1) WTs must be stopped during PM, 2) the profits of the WF are directly related to the wind speed ${ }^{41}$ and 3 ) maintenance activities should be released during low wind speed periods for workers' safety ${ }^{42}$.

Accordingly, the dynamic maintenance policy proposed is focused on fostering the PM activities' release during low wind speed periods by increasing the reliability thresholds; and on the contrary during high wind speed periods, where PM activities' release is hindered by decreasing the reliability thresholds. Therefore, usually two conflicting objectives to be born in the wind energy sector are achieved $^{43}$ : to reduce the wind energy power losses while reducing the total maintenance cost.

In order to define the thresholds variation with regards to the specific operational context, it will be determined by the following factors (see Eq.4-6):

1. Wind speed threshold $(V)$ : determines if the reliability threshold should be decreased or increased by analyzing the forecasted wind speed for the next $p$ periods; if the mean of forecasted wind speed is above $V$ the threshold will be decreased in order to hinder PM, and on the contrary if it is below $V$ (Eq.6).

2. Generated power $\left(G P_{t}\right)$ and reactivity weight $\left(w_{i k}\right)$ : determine the gradient of the reliability thresholds, being directly proportional to the difference between the generated power at each time period $\left(G P_{t}\right)$ and the rated power of WTs $(R P)($ Eq.4,5).

$$
\begin{aligned}
& S R T_{i k j t}=S R T_{i k j} \\
& +\left(2 W_{t}-1\right) \cdot S R T_{i k j} \cdot w_{i k} \cdot\left(\frac{R P}{G P_{t}+R P \cdot W_{t}}\right)^{\left(2 W_{t}-1\right)}
\end{aligned}
$$




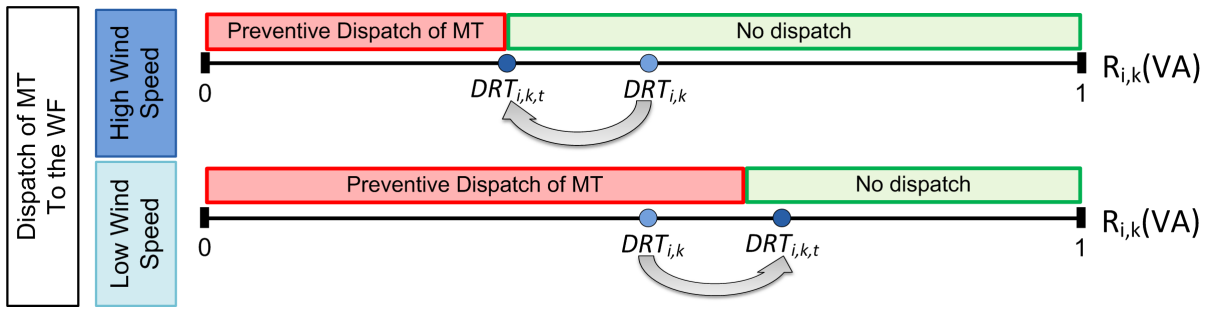

(a) Decision-making structure for the dispatch of the maintenance teams

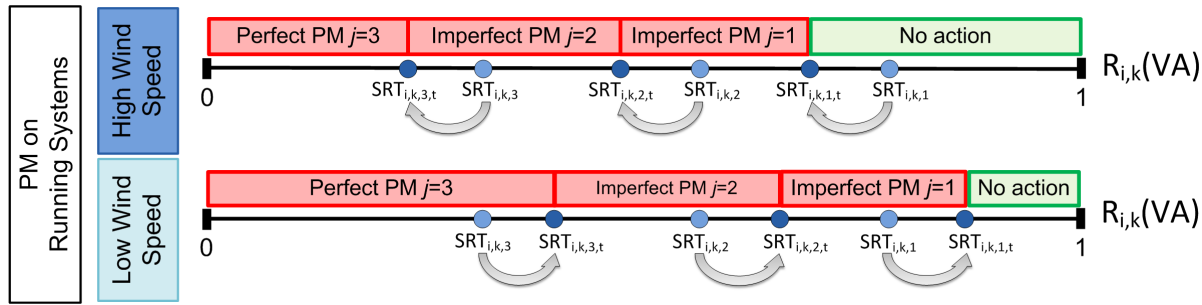

(b) Decision-making structure for performing PM. Example with 3 PM levels per FM

Figure 4. Decision-making structure for the dynamic opportunistic maintenance model

$$
\begin{aligned}
& D R T_{i k t}=D R T_{i k} \\
& +\left(2 W_{t}-1\right) \cdot D R T_{i k} \cdot w_{i k} \cdot\left(\frac{R P}{G P_{t}+R P \cdot W_{t}}\right)^{\left(2 W_{t}-1\right)}
\end{aligned}
$$

$$
W_{t}= \begin{cases}1 & \sum_{l=t}^{t+p} \frac{v_{l}}{p} \leq V \\ 0 & \sum_{l=t}^{t+p} \frac{v_{l}}{p}>V\end{cases}
$$

\subsection{LCC and LP analysis}

In order to make profits from the after-sales service, the OEMs should be able to accurately estimate both the whole LCC of their assets and the service level that they are able to offer to the assets' users, concerning among others: reliability, availability and maintainability (RAM). Accordingly, the main costs to be born in the wind energy sector regarding maintenance and after-sales service, i.e. CM, PM, dispatch and human resources costs, and the offered service level, through the energy-based availability, have been analitycally derived in this Subsection.

According to the CM and PM cost (see Eq.7 and Eq. 8 respectively), material and tools requirements $\left(c_{i k}^{c}, c_{i k j}^{p r}\right)$ and costs due to non availability caused by maintenance have been considered, according to the downtimes $\left(m_{i k}^{c}, m_{i k j}^{p r}\right)$ and the non-generated power during the maintenance period $\left(G P_{t}\right)$, modelled as in Karki and Patel ${ }^{41}$. Whereas in the CM a penalty cost should be considered for commited but not provided power $\left(c^{p}\right)$, in the PM the unique cost associated to the non-available periods is the opportunity cost of not being producing energy $\left(c^{n a}\right)$. As in other reviewed studies ${ }^{44,45}$, the cost of imperfect maintenance has been associated to the restoration factor of the maintenance activity $(q)$.

$z_{h i k t} \cdot\left[c_{i k}^{c} \cdot\left(q_{i k}^{c}\right)^{2}+m_{i k}^{c} \cdot G P_{t} \cdot\left(c^{n a}+c^{p}\right)\right]$ $y_{h i k j t} \cdot\left[c_{i k j}^{p r} \cdot\left(q_{i k j}^{p r}\right)^{2}+m_{i k j}^{p r} \cdot G P_{t} \cdot c^{n a}\right]$

Likewise, every time that maintenance has to be performed, a maintenance team should be dispatched to the WF (Eq.9), which implies a cost $\left(c^{\text {disp }}\right)$. Accordingly, a number of maintenance teams $(N T)$ will be internally hired at a cost $\left(c^{\text {team }}\right)$ by the company in order to perform maintenance. However, if a failure happens and there are no own maintenance teams available for maintenance, external resources $\left(E T_{t}\right)$ should be hired at an extra cost $\left(c^{e t}\right)($ Eq. 10).

$$
\begin{aligned}
& \left(\gamma_{t}+\theta_{t}\right) \cdot c^{d i s p} \\
& E T_{t} \cdot c^{e t}+N T \cdot c^{t e a m}
\end{aligned}
$$

Thereby, considering the long term nature of the LCC analysis, for which the cost has to be properly updated to present value according to the interest rate $\left(k_{a}\right)$, the LCC can be defined as follows (Eq.11).

$$
\begin{aligned}
& \operatorname{LCC}\left(D R T_{i k,} S R T_{i k j}\right)=\left[\sum_{t}\left(\gamma_{t}+\theta_{t}\right) \cdot c^{\text {disp }}\right. \\
& \sum_{h} \sum_{i} \sum_{k} \sum_{t} z_{h i k t}\left[c_{i k}^{c}\left(q_{i k}^{c}\right)^{2}+m_{i k}^{c} \cdot G P_{t}\left(c^{n a}+c^{p}\right)\right]+ \\
& \sum_{h} \sum_{i} \sum_{k} \sum_{j} \sum_{t} y_{h i k j t}\left[c_{i k j}^{p r}\left(q_{i k j}^{p r}\right)^{2}+m_{i k j}^{p r} \cdot G P_{t} \cdot c^{n a}\right] \\
& \left.\sum_{t} E T_{t} \cdot c^{e t}+\sum_{t} N T \cdot c^{\text {team }}\right] \cdot\left(1+k_{a}\right)^{-t}
\end{aligned}
$$

As stated, the OEM should as well be aware of the service level that is able to provide at the mentioned cost. Particularly, in the wind energy sector the service level can be meassured according to the lost power (LP) ${ }^{46}$ (Eq.12). 
Table 2. Intermediate Binary variables utilised in the model

\begin{tabular}{|c|c|}
\hline$z_{\text {hikt }}= \begin{cases}1 & \text { if CM k is performed in system iof WT h in } \\
& \text { periodt } \\
0 & \text { otherwise }\end{cases}$ & $y_{\text {hikjt }}=\left\{\begin{array}{l}1 \quad \text { if PM jis performed in FM kof system } i \\
\text { of WThin periodt } \\
0 \quad \text { otherwise }\end{array}\right.$ \\
\hline$\theta_{t}= \begin{cases}1 & \text { if a } M T \text { is correctively dispatched to } W F \text { in period } t \\
0 & \text { otherwise }\end{cases}$ & $\gamma_{t}=\left\{\begin{array}{l}1 \quad \text { if a MT is preventively dispatched to } W F \text { in period } t \\
0 \quad \text { otherwise }\end{array}\right.$ \\
\hline
\end{tabular}

$$
\begin{aligned}
L P=\sum_{t} G P_{t} \cdot\left(\sum_{h} \sum_{i} \sum_{k} m_{i k}^{c} \cdot z_{h i k t}+\right. & \\
& \left.\sum_{h} \sum_{i} \sum_{k} \sum_{j} m_{i k j}^{p r} \cdot y_{h i k j t}\right)
\end{aligned}
$$

\subsection{Dynamic opportunistic maintenance optimisation model}

The general mathematical formulation of the considered dynamic OM policy (see Figure 4 ) will take the following form, considering the DRT and SRT modelling (Eq.15-17); only a maintenance per WT at a time Eq.18); and the overal long term maintenance strategy performance according to LCC (Eq.11) and Lost Power (LP) (Eq.14):

$O F_{O E M}=$ Minimize $\operatorname{LCC}(X)$

$O F_{A U}=$ Minimize $L P(X)$

S.T.

$$
\begin{aligned}
0 \leq D R T_{i k} & \leq S R T_{i k 1} \leq \ldots \leq S R T_{i k j} \leq \\
& \leq \ldots \leq S R T_{i k J} \leq 1 i \epsilon I, k \epsilon K, j \in J ; t \in T
\end{aligned}
$$

$0 \leq w_{i k} \leq 1 i \epsilon I, k \epsilon K$

$$
\begin{gathered}
0 \leq D R T_{i k t} \leq S R T_{i k 1 t} \leq \ldots \leq S R T_{i k j t} \leq \\
\leq \ldots \leq S R T_{i k J t} \leq 1 i \epsilon I, k \epsilon K, j \epsilon J ; t \epsilon T \\
\sum_{j} y_{h i k j t}+z_{h i k t} \leq 1 h \epsilon H, i \epsilon I, k \epsilon K, t \epsilon T
\end{gathered}
$$

$z_{h i k t}, y_{h i k j t} \epsilon\{0,1\} h \epsilon H, i \epsilon I, k \epsilon K, t \epsilon T, \forall j=1,2$

\subsection{Multi-objective Simulation-based Optimisation: NSGA /I}

Several stochastic processes have to be born within the maintenance model, such as failure occurrence, repair processes and weather conditions; which difficults to analitically solve the presented maintenance problem ${ }^{30,44}$. Thus, in order to accuratelly evaluate the different

maintenance strategies and find optimal solutions, most of the problem has been firstly analitically derived, and secondly implemented in simulation techniques, as commonly done in other researches ${ }^{31,44,47}$.

Particularly, an agent-based simulation has been modelled due to its suitability to handle engineering problems with multi-agent systems ${ }^{48}$, such as the wind energy sector. The simulation process modelled can be summarized in 6 main steps (see Figure 5):

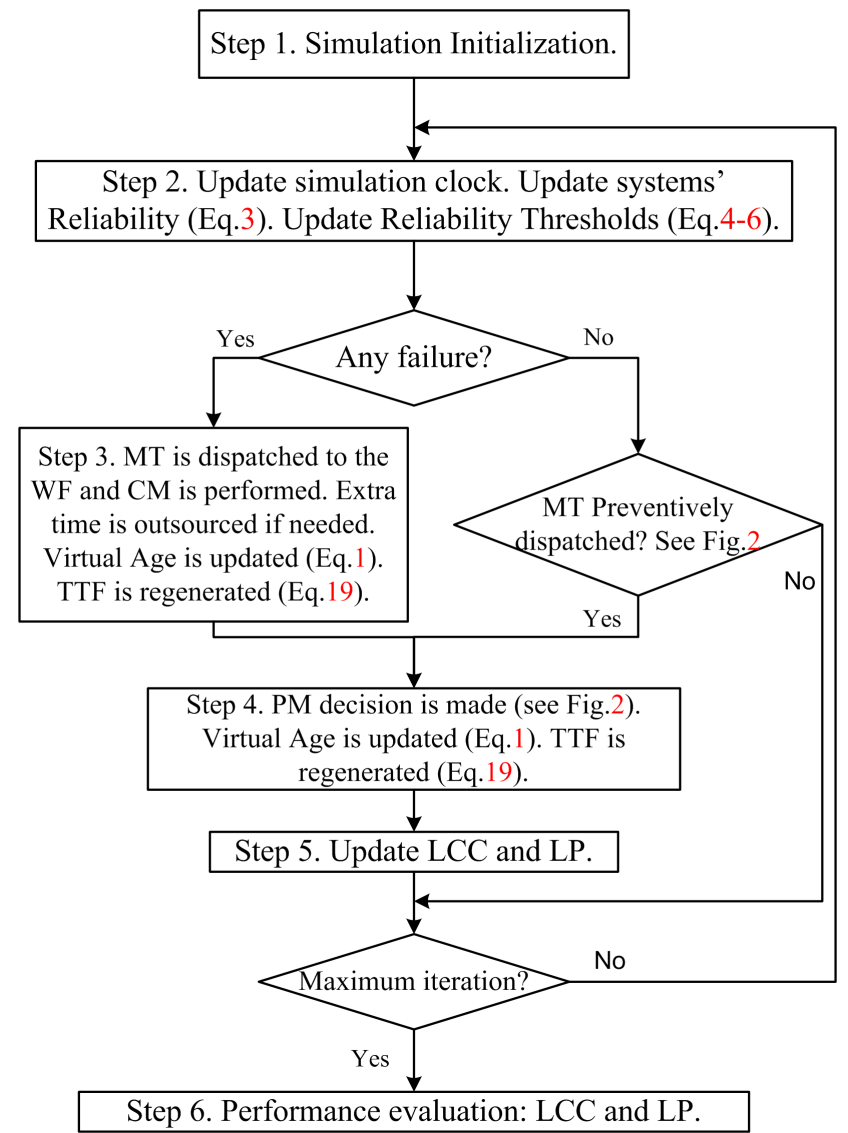

Figure 5. Simulation process for LCC and Energy-based availability evaluation

Step 1. In the simulation initialization the parameters needed for the selection of the maintenance policy and the solution of the maintenance problem are specified. On the one hand, the formers will determine the after-sales service management, namely: reliability and wind speed thresholds, number of maintenance teams, etc. On the other hand, the latters will condition the maintenance solution that are not under the influence of the decision-maker, such as: FMs' failure and maintainability distributions or costs related to maintenance.

Step 2. The simulation clock and virtual age of each FM of the systems are updated, identifying their new reliability according to their age (Eq.3). Likewise, the dynamic 
reliability thresholds are updated according to the wind speed prediction (Eq.4-6).

Step 3. If a failure happens a MT is preventively dispatched to the wind farm to perform CM. If there are not own resources available, maintenance should be outsourced at an extra cost. After restoring the FM, the virtual age of the system is updated and the new time to failure $(T T F)$ is calculated through the Inverse Transform Technique ${ }^{49}$, according to Eq.19, in which $R$ is uniformly distributed between $[0,1)$ (adopted from ${ }^{44}$ ).

$T T F_{h i k}=\alpha_{i k}\left[\left(\frac{V A_{h i k}}{\alpha_{i k}}\right)^{\beta_{i k}}-\ln (1-R)\right]^{\frac{1}{\beta_{i k}}}-V A_{h i k}$

When there is not a failure in the WF, whether a MT should be preventively dispatched to the WF should be decided, according to $D R T_{i k t}$ (Eq.4). In the case a preventive dispatch of a MT is not needed, it should be analysed whether it is the maximum iteration period or not.

Step 4. PM decision is made according to the reliability thresholds $S R T_{i k j t}$ (Eq.5) and the available capacity of own resources. Virtual age of the repaired FMs is updated (Eq.3) and the new time to failure $\left(T T F_{h i k}\right)$ is calculated (Eq.19).

Step 5. LCC and Energy-based availability are updated. If the actual period is equal to the maximum iteration period, step 6 is followed. Otherwise, steps 2,3, 4 and 5 are repeated.

Step 6. The total expected LCC and the average energy-based availability are calculated for the established opportunistic maintenance policy, $L C C=$ $f\left[S R T_{i k j}, D R T_{i k}, w_{i k}, V, p, M T\right]$.

In order to find an optimal set of dynamic reliability thresholds, and since in the after-sales service a trade-off between OEMs' and asset users' objectives should be found, the well known multi-objective metaheuristic NSGA II ${ }^{50}$ has been implemented for the simulation-based optimisation. The NSGA II has already been used for solving several maintenance problems ${ }^{11,51}$ due to the high quality nondominated solutions and the diversity on the Pareto front that it provides ${ }^{52}$.

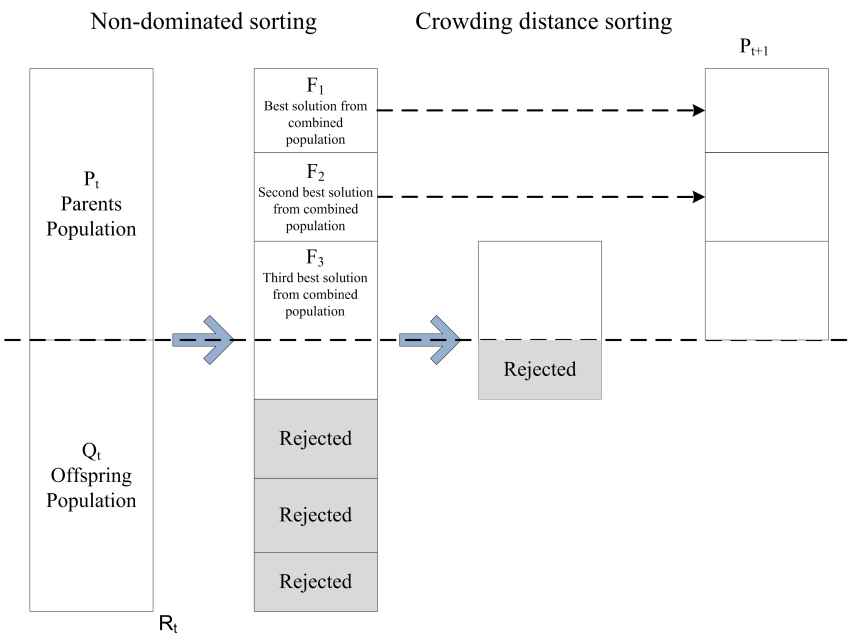

Figure 6. NSGA II procedure adopted from ${ }^{50}$

Figure 6 illustrates the general procedure of NSGA II, which is based on building a population of competing individuals, ranking and sorting each individual according to their nondomination level and creating a new pool of offsprings through Evolutionary Operations. Then, parents and offsprings are combined before partitioning the new combined pool into fronts. The diversity of the population is ensured through the called crowding distance, which evaluates how far is each solution from its neighbours in the front $^{50,53}$

\section{Wind Energy case study}

\subsection{Wind farm profile}

It is considered the case in which the OEM installs a new WF consisting of 50 WTs $(H=50)$ of a rated power of 1,67 megawatt (MW); and the after-sales service will be based on a PBC during the whole life cycle of the assets.

For each WT the 4 most critical systems are considered $(N=4)$, regarding both their reliability and the consequences of their failures, according to the data available for the study. These 4 systems are: blades, gearbox, yaw system and pitch system. For each system three independent FMs are analyzed $(K=3)$. Particularly, $k=1$ FMs of each system are assigned to sensors' false alarms, so they do not have material requirements nor need of field-maintenance. The systems can also undergo two different PM levels $(J=2)$ associated to the FMs $(k=2,3)$, with a restoration factor associated to the maintenance routine $\left(q_{i k 1}^{p r}=0.75\right.$ and $q_{i k 2}^{p r}=$ 1) $\left(\operatorname{see}^{30}\right)$

The access cost to the WF is assumed to be $5000 €$, own resources $800 € /$ day per maintenance team, extra resources $250 € / \mathrm{hr}$ per maintenance team, the total opportunity cost $105 € / \mathrm{MWh}$, the penalization cost $35 € / \mathrm{MWh}$, the interest rate $5 \%$ and the lead time to the WF one hour. Finally, the cost for the materials and the maintainability of PM has been set a 30\% lower than for CM. Further information about material cost for the WT under study can be found on MartinTretton et al. ${ }^{54}$.

Real wind data has been utilised in order to feed the simulation and obtain as much realistic scenarios as possible. The wind turbines cut-in, cut-out and rated speeds are respectively assumed to be $3 \mathrm{~m} / \mathrm{s}, 25 \mathrm{~m} / \mathrm{s}$ and $13 \mathrm{~m} / \mathrm{s}$.

\subsection{Optimisation Results and Discussion}

20 different optimal after-sales maintenance strategies have been found through the previous multi-objective optimisation. Nevertheless, 4 different strategies have been selected in order to 1) illustrate their usefulness for properly deploying an after-sales service, 2) measure the uncertainty propagation and its consequences and 3) offer a successful PBC. (The reader can address the results in Table 3 and the decision variables in Table 5 within Appendix A).

As stated in Subsection 3, due to the several stochastic processes that have to be handled within the after-sales services $^{7}$ such as failure events, there is an inherent uncertainty in the system model that cannot be avoided. These system uncertainties imply variability in the results of the model and a deviation from the optimal solution, which is represented in the sensitivity analysis shown in figure 7.

If an statistical analysis is performed to meassure the uncertainty propagation to the quantities of interest, the 


\begin{tabular}{|c|c|c|c|c|c|c|c|c|c|c|}
\hline & \multicolumn{5}{|c|}{ OEMs’ Quantity of Interest: LCC (€) } & \multicolumn{5}{|c|}{ Asset-Ussers' Quantity of Interest: LP (MWh) } \\
\hline & Mean & St & $L, C I_{\text {mean }}^{95}$ & $U, C I_{\text {mean }}^{95}$ & $F_{U, C I}=0.95$ & Mean & St & $L, C I_{\text {mean }}^{95}$ & $U, C I_{\text {mean }}^{95}$ & $F_{U, C I}=0.95$ \\
\hline S. 18 & $61,7 \mathrm{E} 6$ & 780808 & $61,5 \mathrm{E} 6$ & $61,9 \mathrm{E} 6$ & $63,1 \mathrm{E} 6$ & 51955 & 3461 & 51218 & 52693 & 58386 \\
\hline S. 0 & 63,1 E6 & 687105 & $62,9 \mathrm{E} 6$ & $63,2 \mathrm{E} 6$ & 64,4 E6 & 51680 & 3215 & 50999 & 52361 & 57650 \\
\hline S. 7 & $64,5 \mathrm{E} 6$ & 687806 & $64,3 \mathrm{E} 6$ & $64,6 \mathrm{E} 6$ & $65,8 \mathrm{E} 6$ & 50377 & 2741 & 49800 & 50955 & 55465 \\
\hline S. 11 & $64,9 \mathrm{E} 6$ & 652858 & $64,8 \mathrm{E} 6$ & $65,1 \mathrm{E} 6$ & $66,1 \mathrm{E} 6$ & 46732 & 2839 & 46134 & 47330 & 52001 \\
\hline
\end{tabular}

Table 3. Confidence Intervals for OEMs' and Asset-Ussers' Quantities of Interest

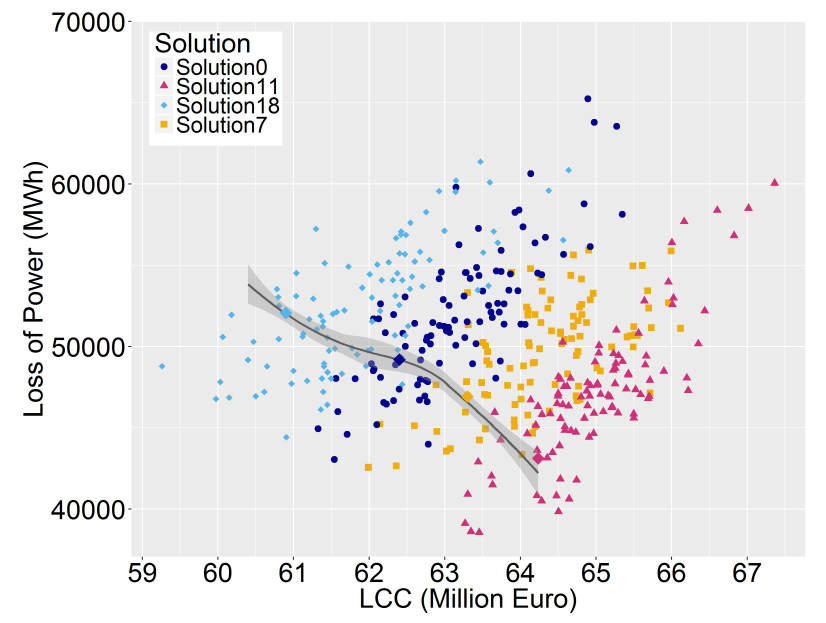

Figure 7. Sensitivity analysis for meassuring optimal results uncertainty provoked by the system model

decision maker will be able to assess the risk that implies following a certain maintenance strategy, and thus, manage them ${ }^{12}$. Moreover, the decision-maker will be able to decide whether they should be more or less cautious when establishing the cost and the service level of the after-sales service.

These results are shown in Table 3, where the mean (with lower and upper confidence intervals (CI)), the standard deviation and the accumulated probability of providing a successful service the $95 \%$ of the times are analyzed. As an example, following the maintenance strategy defined in Solution 7 (S.7), if the life cycle PBC was priced at 65,8 E6 euros and the service level was established at $55465 \mathrm{MWh}$ (during the 20 years of the life cycle), only $5 \%$ of the times would be either the OEM or the asset-user dissatisfied. If the price and the service level were offered at mean values, or without considering the impact of uncertainty sources, there would be a high probability of not providing the commited service level (implying high penalizations) or to exceed the maintenance cost, jeopardizing the after-sales service success.

Therefore, according to the requirements of each assetuser regarding both service-level and cost, the after-sales service decision maker should define the maintenance strategy to be followed (attending to the optimal solutions), and the price and the service level to be offered (attending to the statistical analysis of the uncertainty).

Furthermore, as defined in Section 3, uncertainty sources of the input variables can also condition the success of the deployed service. Likewise, this impact should be quantified and managed as well. With the purpose of analyzing such impact, the uncertainty on the time to repair efficiency has been measured, since it might be conditioned by several factors: problems in the spare parts supply chain, workers' efficiency, maintenance processes design, etc.

The density graphs in Figure 8 confirm how the greater the uncertainty level, the greater the variability on the results of the after-sales service. Thus, if the statistical analysis is performed (see Table 4), it can be noticed that in order to provide an after-sales service within the $95 \%$ confidence level, its quality will considerably decrease, specially in the asset-user quantity of interest where the commited servicelevel should be decreased in more than a $23 \%$. Therefore, the greater the uncertainty sources the less appealing service and PCB that the OEM will be able to offer.

Consequently, and regarding the feedback process shown in Figure 2, the after-sales service decision makers should focus their efforts on improving the after-sales inputs (e.g. repair processes efficiency) and reducing the endogenous sources of uncertainty that condition them. In fact, if an investment is performed for improving the efficiency on the time to repair, benefits with regards to the offered service level is considerably improved (Figure 9).

Such investments will have both a qualitative benefit for the OEM, in terms of offered service level and good corporate image ensuring and enhancing the sales of new assets in the future, and in quantitative terms, due to the saved maintenance cost and the greater price of the PBC. Since these improvements benefit the asset-users as well, variable payment methods are usually established, where both the OEM and the asset-users increase their profits.

\section{Concluding remarks}

After-sales services can be a great source of benefits for OEMs. However, OEMs have usually difficulties in properly defining the after-sales service due to the several factors that have to be considered, such as: services' targets, maintenance policy definition, maintenance strategy optimisation, etc. Furthermore, there are multiple uncertainty sources that might condition the performance of the after-sales services, which are both related to input variables uncertainty and the developed system model itself. 

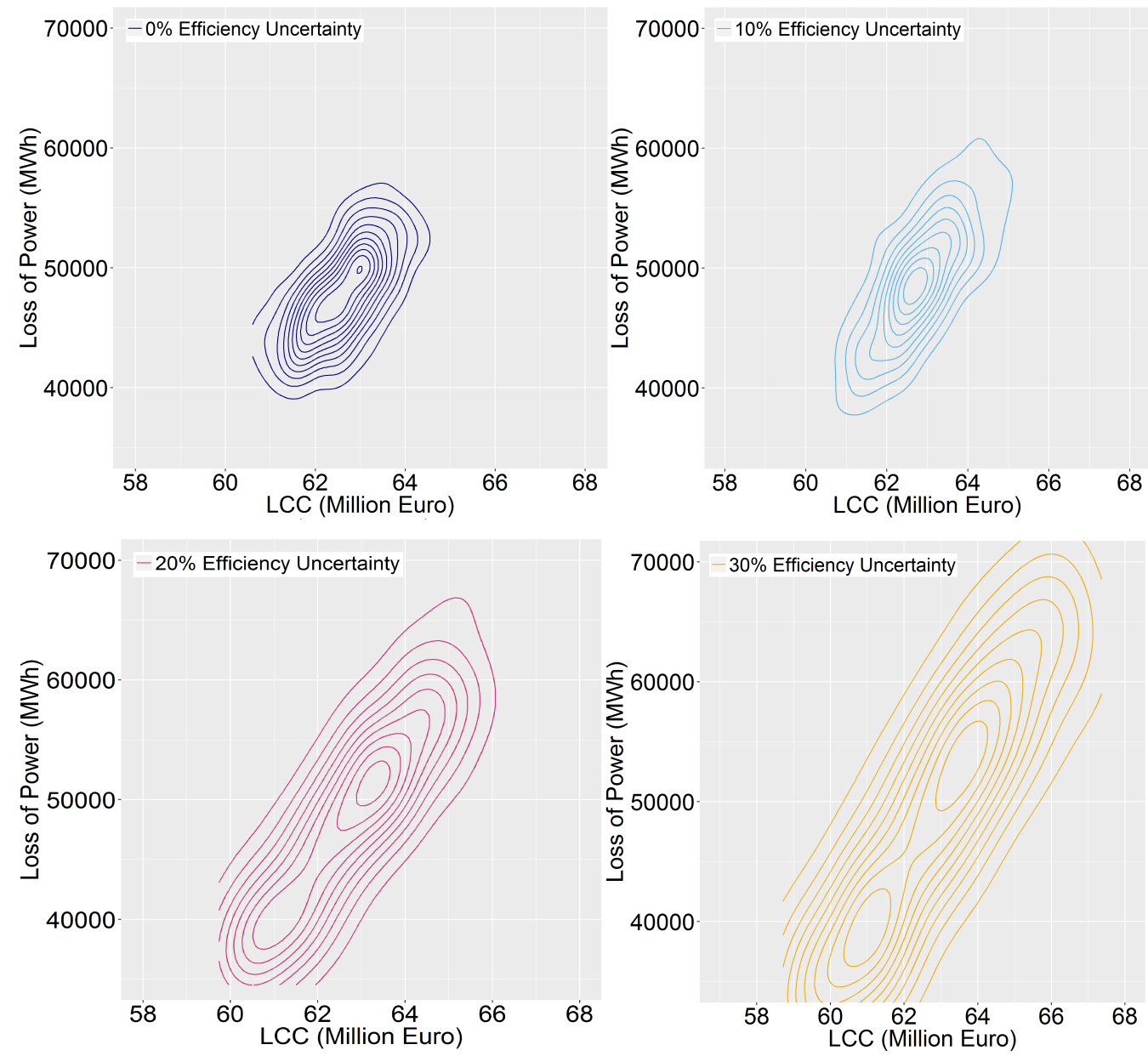

Figure 8. The impact of uncertainty in the time to repair efficiency

\begin{tabular}{|c|c|c|c|c|c|c|c|}
\hline \multicolumn{4}{|c|}{ OEMs' Quantity of Interest LCC (Euro) } & \multicolumn{4}{|c|}{ Asset-Ussers' Quantity of Interest LP (MWh) } \\
\hline$U, C I_{\text {mean }}^{95}$ & St & $F_{U, C I}=0.95$ & $\Delta \%$ & Mean & St & $F_{U, C I}=0.95$ & $\Delta \%$ \\
\hline 63,2 E6 & 687105 & 64,4 E6 & - & 48354 & 3833 & 54659 & - \\
\hline 63,0 & 1100646 & 64,8 E6 & 0,6 & 49719 & 4921 & 57814 & 5,77 \\
\hline 62,9 & 1517755 & 65,4 E6 & 1,55 & 49481 & 7865 & 62419 & 14,2 \\
\hline 63,0 & 2102454 & 66,4 E6 & 3,1 & 50097 & 10789 & 67418 & 23,34 \\
\hline
\end{tabular}

Table 4. Confidence Intervals for OEMs' and Asset-Ussers' Quantities of Interest given an uncertainty in the time to repair efficiency

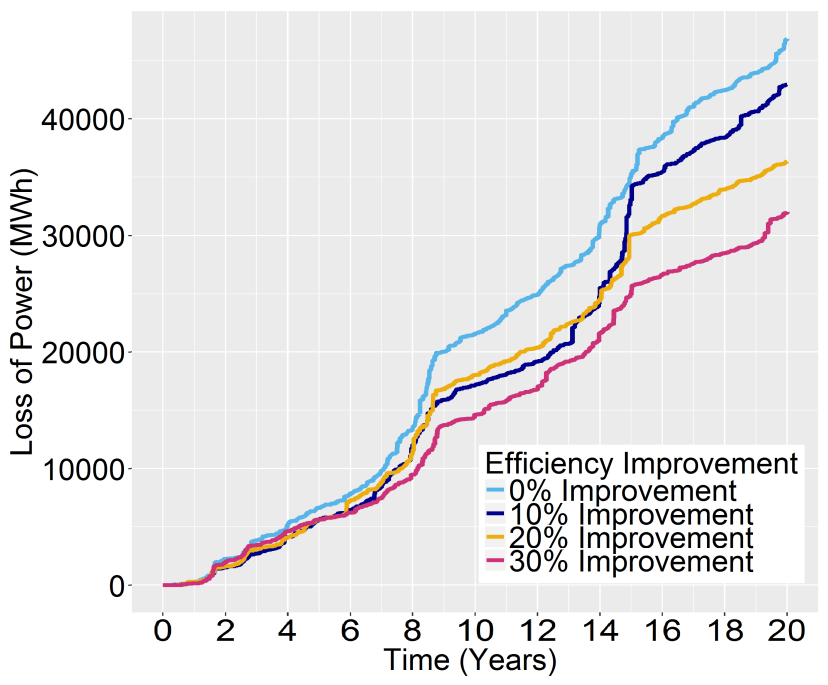

Figure 9. Impact of improving time to repair efficiency on the offered service level Prepared using sagej.cls
Therefore, the present paper provides methodologycal insights for properly categorising the impact of the uncertainty sources and offering successful after-sales service performance-based contracts. To this aim, the whole system modelling is covered, from the maintenance problem modelling to the after-sales service definition, illustrating it for the wind-energy case study.

The results obtained demonstrate that when these uncertainty sources are not suitably identified and quantified, there is a high risk of both not being able to provide the offered service level and exceeding the cost of the service; consequently, turning the after-sales services into a loss source instead of an incomes source.

Future efforts will focus on how the uncertainty provoked by random inputs that directly affect the after-sales service should be addressed. Likewise, further research might concentrate on the development of a more generic system 
modelling allowing to manage the after-sales maintenance service regardless the sector under study.

\section{Funding}

This research work was performed within both the context of the SustainOwner ('Sustainable Design and Management of Industrial Assets through Total Value and Cost of Ownership'), a project sponsored by the EU Framework Programme Horizon 2020, MSCA-RISE-2014: Marie Skłodowska-Curie Research and Innovation Staff Exchange (RISE) (grant agreement number 645733Sustain-Owner-H2020-MSCA-RISE-2014) and the EmaitekPlus 2016-2017 Program of the Basque Government.

\section{References}

1. Öner K, Kiesmüller G and van Houtum G. Optimization of component reliability in the design phase of capital goods. European Journal of Operational Research 2010; 205(3): 615624. DOI:10.1016/j.ejor.2010.01.030. Cited By 39.

2. Cohen $\mathrm{M}$ and Whang S. Competing in product and service: A product life-cycle model. Management Science 1997; 43(4): 535-545. Cited By 89.

3. González-Prida V and Márquez AC. A framework for warranty management in industrial assets. Computers in Industry 2012; 63(9): 960 - 971. DOI:http://dx.doi.org/10.1016/j.compind. 2012.09.001.

4. Su C and Wang X. Modeling flexible two-dimensional warranty contracts for used products considering reliability improvement actions. Proceedings of the Institution of Mechanical Engineers, Part O: Journal of Risk and Reliability 2016; 230(2): 237-247. DOI:10.1177/1748006X15627395.

5. Sagarna I, Uribetxebarria J, Castellano E et al. After-sales maintenance service strategies optimization. an offshore wind farm case study. IFAC-PapersOnLine 2016; 49(28): 156-161. DOI:10.1016/j.ifacol.2016.11.027. Cited By 0.

6. Kim SH, Cohen MA and Netessine S. Reliability or inventory? contracting strategies for after-sales product support. In Proceedings of 2007 International Conference on Manufacturing \& Service Operations Management.

7. Kim SH, Cohen M and Netessine S. Performance contracting in after-sales service supply chains. Management Science 2007; 53(12): 1843-1858. DOI:10.1287/mnsc.1070.0741. Cited By 160.

8. Xie M, Li X and Ng S. Risk-based software release policy under parameter uncertainty. Proceedings of the Institution of Mechanical Engineers, Part O: Journal of Risk and Reliability 2011; 225(1): 42-49. DOI:10.1177/1748006XJRR286.

9. Laggoune R, Chateauneuf A and Aissani D. Impact of few failure data on the opportunistic replacement policy for multicomponent systems. Reliability Engineering \& System Safety 2010; 95(2): 108-119. DOI:10.1016/j.ress.2009.08.007.

10. Zhu W, Fouladirad $M$ and Bérenguer C. A multi-level maintenance policy for a multi-component and multifailure mode system with two independent failure modes. Reliability Engineering \& System Safety 2016; 153: 50-63. DOI:10.1016/ j.ress.2016.03.020.

11. Attar A, Raissi S and Khalili-Damghani K. A simulation-based optimization approach for free distributed repairable multistate availability-redundancy allocation problems. Reliability Engineering \& System Safety 2017; 157: 177-191. DOI: 10.1016/j.ress.2016.09.006.
12. de Rocquigny E, Devictor N and Tarantola S. Uncertainty in industrial practice: a guide to quantitative uncertainty management. John Wiley \& Sons, 2008.

13. Macfarlan W and Mansir B. Supporting the warfighter through performance-based contracting. defense standardiza tion program j.(july/september) 38-43, 2004.

14. Jin T, Ding Y, Guo $\mathrm{H}$ et al. Managing wind turbine reliability and maintenance via performance-based contract. DOI:10. 1109/PESGM.2012.6344739. Cited By 7.

15. Jin $\mathrm{T}$ and Wang P. Planning performance based contracts considering reliability and uncertain system usage. Journal of the Operational Research Society 2012; 63(10): 1467-1478. DOI:10.1057/jors.2011.144.

16. Nowicki D, Kumar U, Steudel $\mathrm{H}$ et al. Spares provisioning under performance-based logistics contract: Profit-centric approach. Journal of the Operational Research Society 2008; 59(3): 342-352. DOI:10.1057/palgrave.jors.2602327. Cited By 35 .

17. De Weck O, Eckert $\mathrm{C}$ and Clarkson J. A classification of uncertainty for early product and system design. Cited By 52 .

18. 31000:2009 risk management - principles and guidelines.

19. Villanueva J, Sanchez A, Carlos S et al. Genetic algorithmbased optimization of testing and maintenance under uncertain unavailability and cost estimation: A survey of strategies for harmonizing evolution and accuracy. Reliability Engineering \& System Safety 2008; 93(12): 1830 - 1841. DOI:http://dx. doi.org/10.1016/j.ress.2008.03.014. 17th European Safety and Reliability Conference.

20. Sanchez A, Carlos S, Martorell S et al. Addressing imperfect maintenance modelling uncertainty in unavailability and cost based optimization. Reliability Engineering \& System Safety 2009; 94(1): 22 - 32. DOI:http://dx.doi.org/10.1016/j.ress. 2007.03.022. Maintenance Modeling and Application.

21. Wang H. A survey of maintenance policies of deteriorating systems. European Journal of Operational Research 2002; 139(3): 469-489. DOI:10.1016/s0377-2217(01)00197-7.

22. Nicolai $R$ and Dekker R. A review of multi-component maintenance models. In Proceedings of European Safety and Reliability Conference. pp. 289-296.

23. Shi $\mathrm{H}$ and Zeng J. Real-time prediction of remaining useful life and preventive opportunistic maintenance strategy for multi-component systems considering stochastic dependence. Computers \& Industrial Engineering 2016; 93: 192-204. DOI: 10.1016/j.cie.2015.12.016.

24. Keizer MCO, Teunter RH and Veldman J. Clustering condition-based maintenance for systems with redundancy and economic dependencies. European Journal of Operational Research 2016; 251(2): 531-540. DOI:10.1016/j.ejor.2015. 11.008.

25. Ba HT, Cholette M, Borghesani P et al. Opportunistic maintenance considering non-homogenous opportunity arrivals and stochastic opportunity durations. Reliability Engineering \& System Safety 2017; 160: 151-161. DOI:10.1016/j.ress.2016. 12.011.

26. Tian Z, Jin T, Wu B et al. Condition based maintenance optimization for wind power generation systems under continuous monitoring. Renewable Energy 2011; 36(5): 15021509. DOI:10.1016/j.renene.2010.10.028.

27. Atashgar $\mathrm{K}$ and Abdollahzadeh H. Reliability optimization of wind farms considering redundancy and opportunistic maintenance strategy. Energy Conversion and Management 
2016; 112: 445-458. DOI:10.1016/j.enconman.2016.01.027.

28. Hameed $\mathrm{Z}$ and Vatn J. Role of grouping in the development of an overall maintenance optimization framework for offshore wind turbines. Proceedings of the Institution of Mechanical Engineers, Part O: Journal of Risk and Reliability 2012; 226(6): 584-601. DOI:10.1177/1748006X1246461.

29. Shafiee $M$ and Finkelstein $M$. A proactive group maintenance policy for continuously monitored deteriorating systems: Application to offshore wind turbines. Proceedings of the Institution of Mechanical Engineers, Part O: Journal of Risk and Reliability 2015; 229(5): 373-384. DOI:10.1177/ 1748006 X15598915.

30. Ding F and Tian Z. Opportunistic maintenance for wind farms considering multi-level imperfect maintenance thresholds. Renewable Energy 2012; 45: 175-182. DOI:10.1016/j.renene. 2012.02.030.

31. Sarker BR and Faiz TI. Minimizing maintenance cost for offshore wind turbines following multi-level opportunistic preventive strategy. Renewable Energy 2016; 85: 104-113. DOI:10.1016/j.renene.2015.06.030.

32. Pham $\mathrm{H}$ and Wang $\mathrm{H}$. Imperfect maintenance. European Journal of Operational Research 1996; 94(3): 425-438. DOI: 10.1016/s0377-2217(96)00099-9.

33. Yañez M, Joglar F and Modarres M. Generalized renewal process for analysis of repairable systems with limited failure experience. Reliability Engineering \& System Safety 2002; 77(2): 167-180. DOI:10.1016/S0951-8320(02)00044-3.

34. Karyotakis A. On the optimisation of operation and maintenance strategies for offshore wind farms. $\mathrm{PhD}$ Thesis, University College London (UCL), 2011.

35. Andrawus JA. Maintenance optimisation for wind turbines. PhD Thesis, The Robert Gordon University, 2008.

36. Stamatelatos M, Dezfuli H, Apostolakis G et al. Probabilistic risk assessment procedures guide for nasa managers and practitioners 2011; .

37. Byon E, Ntaimo L and Ding Y. Optimal maintenance strategies for wind turbine systems under stochastic weather conditions. IEEE Transactions on Reliability 2010; 59(2): 393-404. DOI: 10.1109/tr.2010.2046804.

38. Erguido A, Márquez AC, Castellano E et al. A novel dynamic opportunistic maintenance modelling approach. In European Safety and Reliability Conference (ESREL) 2017.

39. Abdollahzadeh $\mathrm{H}$ and Atashgar K. Optimal design of a multistate system with uncertainty in supplier selection. Computers \& Industrial Engineering 2017; 105: 411-424. DOI:10.1016/ j.cie.2017.01.019.

40. Shafiee $M$ and Finkelstein M. A proactive group maintenance policy for continuously monitored deteriorating systems: Application to offshore wind turbines. Proceedings of the Institution of Mechanical Engineers, Part O: Journal of Risk and Reliability 2015; 229(5): 373-384. DOI:10.1177/ 1748006x15598915.

41. Karki R and Patel J. Reliability assessment of a wind power delivery system. Proceedings of the Institution of Mechanical Engineers, Part O: Journal of Risk and Reliability 2008; 223(1): 51-58. DOI:10.1243/1748006xjrr218.

42. Carlos S, Sánchez A, Martorell S et al. Onshore wind farms maintenance optimization using a stochastic model. Mathematical and Computer Modelling 2013; 57(7-8): 18841890. DOI:10.1016/j.mcm.2011.12.025.
43. Iqbal M, Azam M, Naeem M et al. Optimization classification, algorithms and tools for renewable energy: A review. Renewable and Sustainable Energy Reviews 2014; 39: 640654. DOI:10.1016/j.rser.2014.07.120.

44. Abdollahzadeh $\mathrm{H}$, Atashgar $\mathrm{K}$ and Abbasi M. Multiobjective opportunistic maintenance optimization of a wind farm considering limited number of maintenance groups. Renewable Energy 2016; 88: 247-261. DOI:10.1016/j.renene. 2015.11.022.

45. Ding F and Tian Z. Opportunistic maintenance optimization for wind turbine systems considering imperfect maintenance actions. International Journal of Reliability, Quality and Safety Engineering 2011; 18(05): 463-481. DOI:10.1142/ s0218539311004196.

46. González E, Nanos EM, Seyr H et al. Key performance indicators for wind farm operation and maintenance. Scientific report, 1st Joint Industry Workshop, 2016.

47. Zille V, Bérenguer C, Grall A et al. Modelling multicomponent systems to quantify reliability centred maintenance strategies. Proceedings of the Institution of Mechanical Engineers, Part O: Journal of Risk and Reliability 2011; 225(2): 141-160. DOI:10.1177/1748006X11402269.

48. Niazi $M$ and Hussain A. Agent-based computing from multi-agent systems to agent-based models: a visual survey. Scientometrics 2011; 89(2): 479-499. DOI:10.1007/ s11192-011-0468-9.

49. Banks J. Discrete event simulation. In Encyclopedia of Information Systems. Elsevier BV, 2003. pp. 663-671. DOI: 10.1016/b0-12-227240-4/00045-9.

50. Deb K, Pratap A, Agarwal $S$ et al. A fast and elitist multiobjective genetic algorithm: NSGA-II. IEEE Transactions on Evolutionary Computation 2002; 6(2): 182197. DOI:10.1109/4235.996017.

51. Safari J. Multi-objective reliability optimization of seriesparallel systems with a choice of redundancy strategies. Reliability Engineering \& System Safety 2012; 108: 10-20. DOI:10.1016/j.ress.2012.06.001.

52. Salazar D, Rocco CM and Galván BJ. Optimization of constrained multiple-objective reliability problems using evolutionary algorithms. Reliability Engineering \& System Safety 2006; 91(9): 1057-1070. DOI:10.1016/j.ress.2005.11. 040 .

53. Coello CAC, Lamont GB, Van Veldhuizen DA et al. Evolutionary algorithms for solving multi-objective problems, volume 5. Springer, 2007.

54. Martin-Tretton M, Reha M, Drunsic M et al. Data collection for current us wind energy projects: Component costs, financing, operations, and maintenance. Contract 2012; 303: 275-3000.

\section{Appendix A}

Numerical experiments illustrated through the paper correspond to the following solutions. 


\section{Gearbox}

\begin{tabular}{rccccccccccc}
\hline Sol. & $S R T_{121}$ & $S R T_{122}$ & $D R T_{12}$ & $w_{12}$ & $S R T_{131}$ & $S R T_{132}$ & $D R T_{13}$ & $w_{13}$ & $M T$ & $p$ & $V$ \\
\hline S. 0 & 0.86 & 0.42 & 0.35 & 0.60 & 0.98 & 0.61 & 0.24 & 0.99 & 2 & 4 & 0.5 \\
S. 7 & 0.77 & 0.43 & 0.40 & 0.76 & 0.76 & 0.47 & 0.03 & 0.34 & 3 & 5 & 0.5 \\
S. 11 & 0.84 & 0.44 & 0.15 & 0.56 & 0.98 & 0.43 & 0.05 & 0.34 & 3 & 4 & 1 \\
S. 18 & 0.85 & 0.56 & 0.03 & 0.51 & 0.74 & 0.38 & 0.25 & 0.13 & 2 & 3 & 0.5 \\
\hline
\end{tabular}

Pitch

\begin{tabular}{rcccccccc}
\hline Sol. & $S R T_{221}$ & $S R T_{222}$ & $D R T_{22}$ & $w_{22}$ & $S R T_{231}$ & $S R T_{232}$ & $D R T_{23}$ & $w_{23}$ \\
\hline S. 0 & 0.82 & 0.61 & 0.44 & 0.39 & 0.98 & 0.65 & 0.48 & 0.22 \\
S. 7 & 0.93 & 0.65 & 0.08 & 0.80 & 0.98 & 0.62 & 0.05 & 0.2 \\
S. 11 & 0.96 & 0.67 & 0.30 & 0.66 & 0.98 & 0.70 & 0.33 & 0.44 \\
S. 18 & 0.96 & 0.59 & 0.38 & 0.4 & 0.97 & 0.62 & 0.45 & 0.16 \\
\hline \multicolumn{7}{c}{ Yaw }
\end{tabular}

\begin{tabular}{ccccccccc}
\cline { 2 - 8 } Sol. & $S R T_{321}$ & $S R T_{322}$ & $D R T_{32}$ & $w_{32}$ & $S R T_{331}$ & $S R T_{332}$ & $D R T_{33}$ & $w_{33}$ \\
\hline S. 0 & 0.79 & 0.62 & 0.10 & 0.31 & 0.93 & 0.16 & 0.01 & 0.49 \\
S. 7 & 0.92 & 0.26 & 0.10 & 0.95 & 0.93 & 0.40 & 0.10 & 0.96 \\
S. 11 & 0.90 & 0.68 & 0.12 & 0.83 & 0.93 & 0.71 & 0.16 & 0.60 \\
S. 18 & 0.79 & 0.51 & 0.725 & 0.33 & 0.94 & 0.73 & 0.09 & 0.37 \\
\hline
\end{tabular}

Blades

\begin{tabular}{ccccccccc}
\cline { 2 - 8 } Sol. & $S R T_{421}$ & $S R T_{422}$ & $D R T_{42}$ & $w_{42}$ & $S R T_{431}$ & $S R T_{432}$ & $D R T_{43}$ & $w_{43}$ \\
\hline S. 0 & 0.95 & 0.49 & 0.27 & 0.68 & 0.92 & 0.39 & 0.05 & 0.54 \\
S. 7 & 0.91 & 0.50 & 0.43 & 0.53 & 0.88 & 0.62 & 0.23 & 0.37 \\
S. 11 & 0.91 & 0.56 & 0.35 & 0.15 & 0.86 & 0.37 & 0.14 & 0.46 \\
S. 18 & 0.92 & 0.54 & 0.01 & 0.49 & 0.84 & 0.30 & 0.09 & 0.01 \\
\hline
\end{tabular}

Table 5. Confidence Intervals for OEMs' and Asset-Ussers' Quantities of Interest 